\title{
Using Constructivist Approach to Enhance Understanding of Mole Concept among Second Year Students in Chemistry at Adobewura Senior High School in Ashanti Region, Ghana
}

\author{
${ }^{1}$ Kennedy Ameyaw Baah ${ }^{*},{ }^{2}$ Frank Owusu Ansah, ${ }^{3}$ Stephen Kwame Amoako, ${ }^{4}$ Solomon Boachie, \\ ${ }^{5}$ Christian Kwarteng \\ ${ }^{1,2}$ Science Department, Wesley College of Education, Kumasi, Ghana \\ ${ }^{3}$ Science Department, St. Monica's College of Education, Mampong, Ghana \\ ${ }^{4}$ Science Department, St. Ambrose College of Education, Dormaa-Akwamo, Ghana \\ ${ }^{5}$ Science Department, Adobewura Senior High School, Nyinahin, Ghana
}

\begin{abstract}
The aim of the research was to use constructivist approach to enhance performance of second year elective science students of Adobewura in mole concept. In order to achieve this, the researcher employed the following research questions; What methods do teachers use to teach mole concept and to what extent can constructivist approach be used to help students understand mole concept. Action research was used since action research is a way of assessing result while operating. Purposive sampling was used to select 30 students for the study. Data were collected through tests (pre-intervention and post-intervention tests). The scores of the pre and post intervention tests were compared and result analyzed. The analyzed results indicated that students' performance had improved remarkably after the implementation of all the intervention. For instance, when the researcher implemented the demonstration techniques, 23 students scored marks within 41-90 representing $76.67 \%$ while $23.33 \%$ scored between $41-30$. No student scored marks less than 30 marks. Based on the findings of the study, it can be concluded that there are a lot of performance enhancements in using constructivist approach in teaching and learning mole concept at Adobewura SHS since it improves conceptual understanding and also there is a positive effect on students' attitudes of mole concept. The researcher recommends that the use of constructivist approach in teaching and learning chemistry at the Senior High School should be encouraged by Curriculum developers and education implementers for students should have a hands-on experience with mole concept in learning chemistry.
\end{abstract}

Keywords: Constructivist, Mole Concept, Demonstration, Purposive sampling, Intervention.

\subsection{Introduction}

The mole concept has been recognized as one of the most difficult topics to teach and learn within the chemistry curriculum due to its abstract, theoretical nature (Shadreck and Enunuwe, 2018).Students who do not fully understand mole concept experience difficulties in understanding the subsequent topics (Kamarudin, 2014).

Findings indicated by Indriyanti (2016), showed that students fail to construct meaningful understandings of the mole concept for the following reasons: inconsistency between the instructional approaches of the textbook and teacher; confusing mole concept vocabulary; students' math anxiety and proportional reasoning ability; learners' cognitive levels; and lack of practice in problem solving.

Ayoade (2012), said that 'active engagement of the learner with the learning environment, focusing on the learner rather than teacher, and acknowledging (as well as challenging) learners' understanding/intellectual development are useful pedagogical strategies that can facilitate meaningful learning'. Also, according to Olusegun (2015), one of the most important principles in the psychology of learning is that students should construct their own knowledge in mind. Since, students come to school with a rich perception of the world 
around them; there is the need to help students give meaning to the experiences they exposed themselves within the environment. Thus, the students are to be supported so as to discover, discuss and interpret knowledge by themselves.

Constructivist approaches in teaching and learning of science are applied in order to enable students to make meaningful connections between significant new knowledge and transient (Driver, R., Asoko, H., Leach, J., Mortimer, E. and Scott, P. (1994).Thus, constructing an understanding requires that students have opportunities to articulate their ideas, test those ideas through experimentation and classroom discussion, and consider connections between the phenomena they are examining and other aspects of their live (Wilhelm, Friedman and Erickson, 1998).

DeQuadros, A. L., Da-Silva, D. C., Silva, F. C., de Andrade, F. P., Aleme, H. G., Tristão, J. C., Oliveira, S. R., Santos, L.S. and DeFreitas-Silva, G. (2011) consider that the greatest problem in teaching chemistry is the way that concepts are introduced. Many teachers' practice is currently restricted to a rigid curriculum characterized by disconnected content, a lack of interdisciplinary, and mainly a lack of connection with students' reality. This devalues the classroom, which should be a place of construction and change, both for the students and for the teachers themselves (Strack, et al., 2009).This research therefore seeks to use constructivist approach to enhance performance of mole concept in second year elective science students of Adobewura Senior High School.

\subsection{Statement of the Problem}

The United Nations Education Scientific and Cultural Organization (UNESCO) and the International Union of Pure and Applied Chemists (IUPAC) have participated in numerous international meetings to promote inexpensive experimental-based teaching in chemistry (Bello, 2018). However, Mole concept which is one of the topics aimed at equiping students with some cognitive skills and practical skills poses a massive challenge to students. Students who do not fully understand the mole concept experience difficulties in understanding the subsequent topics. For instance, students who do not fully understand the mole concept find it difficult to understand topics like stoichiometry which include volumetric calculations and concentration of solutions. Most second year elective science students of Adobewura cannot comprehend the subject matter and their performances are below average. This is of great concern to school authorities and nation at large.

\subsection{Purpose of the Study}

The purpose of the study was to use constructivist approach to enhance the performance of second year elective science students of Adobewura in the mole concept.

\subsection{Research Questions}

Based on the purpose of the study, the following research question was used;

To what extent can constructivist approach be used to help students understand mole concept?

\section{Methodology}

The research design for the study was an action research. Action research is a disciplined inquiry in which a personal attempt is made to understand, improve and reform practice (Jashim, 2009). Action research is a way of assessing result while operating. The Process is repeated again and again. Thus action research is never ending process as most problems are not fully solved through a single research (Yasmeen, 2008). Population is the total number of person inhabiting a country, city, or an area (Jennifer, 2002). On the part of Polit and Hungler (1999), population is the sum totality or aggregate of phenomenon of interest to the reseacher. The second-year elective science students of Adobewura Senior High School formed the population under this study. Most of the students have their ages ranging from fourteen to twenty-one years. Since, action research focuses on designing an intervention to solve problem in a specific situation, second year elective science students' class was the sample that was deemed appropriate for the purpose of the study. Thirty (30) students were sampled for the study. The sampling method selected was purposive sampling. This is because the researcher teaches there and that was where the problem was identified. The research instruments used was test. The test which was also called chemistry achievement test (CAT) was based on quantitative aspects of mole concept, which was in the form of the pre- and post-test for determining the learners' conceptions were administered in this study. The test was developed by researcher 
by examining related literature, and textbooks. The test consisted of five (5) open-ended questions, with different cognitive levels. The data collected through the CAT were analysed in terms of quantitative description. Most of the questions in the test required learners to think critically; that is, with doing some calculation. The tests were used in the data collection procedure to explore basic concepts of mole and how learners apply mole concept in related topics. Data Analysis was based on the information collected from the chemistry achievement tests. The responses were examined and analyzed. Statistical representation was used in tabulations of the results. The results were analysed into percentages to make interpretation of it meaningful and valid.

\section{Results and Discussion}

Table 4. 1: Demographic Characteristics of Second Year Elective Science Students

\begin{tabular}{|l|l|l|l|}
\hline Gender & Age & Frequency & Percentages (\%) \\
\hline Female & $15-19$ & 12 & 40 \\
\hline Male & $14-22$ & 18 & 60 \\
\hline Total & & 30 & 100 \\
\hline
\end{tabular}

Source: Researcher's field survey, 2019

Table 4.2; shows that, the majority of the respondents were male who were between the ages of $14-22$ representing $60 \%$ of the sample while $40 \%$ of the female whose ages were between $15-19$ were studied. Age distribution should be considered critical when deciding on the intervention to be used.

4.5 Research Question 1: To What Extent Can Constructivist Approach be Used to Help Students Understand Mole Concept?

Pre-test and post-test were used to assess the students' performances in mole concept

\subsection{Pre- intervention Test Score}

The understanding of mole concept in chemistry is very important. This is because without adequate exposure to mole concept, students cannot understand related topics like volumetric analysis, acid and bases etc. the results shows earlier performance of students before the intervention.

Table 4. 2: Pre-Intervention Test Score

\begin{tabular}{|l|l|l|}
\hline SCORE & FREQUENCY & PERCENTAGE \\
\hline $0-10$ & 0 & 0.00 \\
\hline $11-20$ & 2 & 6.67 \\
\hline $21-30$ & 2 & 6.67 \\
\hline $31-40$ & 11 & 36.67 \\
\hline $41-50$ & 8 & 26.67 \\
\hline $51-60$ & 5 & 16.67 \\
\hline $61-70$ & 1 & 3.33 \\
\hline $71-80$ & 1 & 3.33 \\
\hline $81-90$ & 0 & 0.00 \\
\hline $91-100$ & 0 & 0.00 \\
\hline TOTAL & $\mathbf{3 0}$ & $\mathbf{1 0 0}$ \\
\hline
\end{tabular}

Source: Researcher's field survey, 2019 


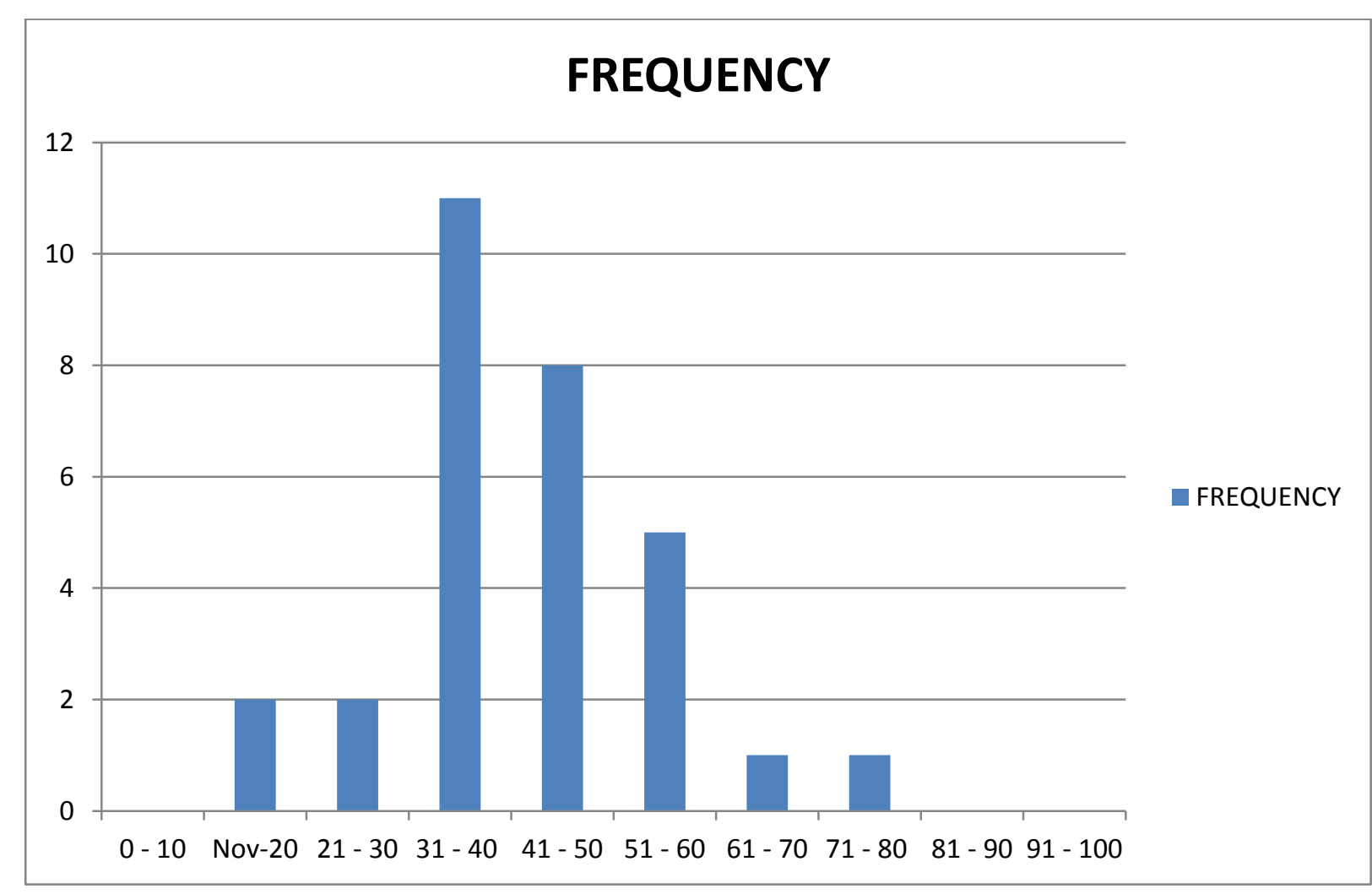

Figure 4.1 Histogram of Pre-Intervention Test Score

The Table 4.3; above shows the pre-intervention test score of students. None of the student scored above (81) marks. Only one student score (71-80) marks representing 3.33\%. Again, One student representing $3.33 \%$ also had 61-70 marks. 5 students scored (51-60) marks. 76.67\% representing 23 students scored below average mark. The poor performance of the students in the pre-intervention test called for the need to put in effective measures to solve the problem.

\subsection{Post Intervention Test Score}

Constructivist approach of teaching was adopted by the researcher in teaching mole concept.

\section{Table 4.3: Post-Intervention Test Score}

\begin{tabular}{|l|l|l|}
\hline SCORE & FREQUENCY & PERCENTAGES \\
\hline $0-10$ & 0 & 0.00 \\
\hline $11-20$ & 0 & 0.00 \\
\hline $21-30$ & 2 & 6.67 \\
\hline $31-40$ & 2 & 6.67 \\
\hline $41-50$ & 4 & 13.33 \\
\hline $51-60$ & 2 & 6.67 \\
\hline $61-70$ & 7 & 23.33 \\
\hline $71-80$ & 8 & 26.67 \\
\hline $81-90$ & 4 & 13.33 \\
\hline $91-100$ & 1 & 3.33 \\
\hline TOTAL & $\mathbf{3 0}$ & $\mathbf{1 0 0}$ \\
\hline
\end{tabular}

Source: Researcher's field survey,2019 


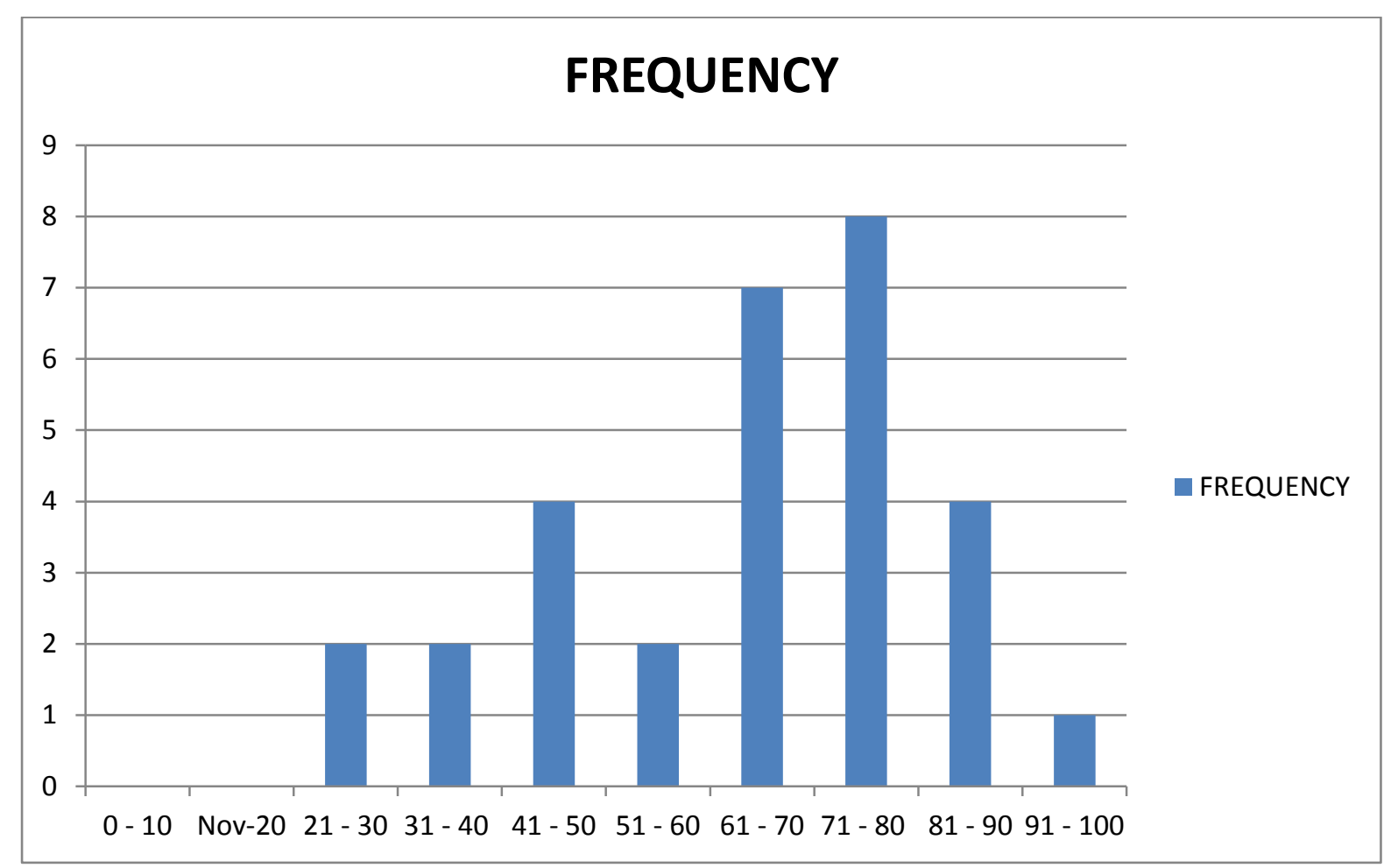

\section{Figure 4.2 Histogram of Post-Intervention Test Score}

Table 4.4; shows that 12 students representing 43.33\% had 71-100 marks. Eight (8) students had below average with no student scoring below 20. From the table, it can be ascertained that respondent's score are very encouraging as compared to the prê-test.

\subsection{Comparison of the Scores at Pre-Intervention Test and Post-Intervention Test}

In order to find how best the intervention has help in solving the problem, it was important to analyse the result between the pre-intervention score and post-intervention score.

\section{Table 4.4: Pre-Intervention and Post-Intervention Test Score}

\begin{tabular}{|l|l|l|l|l|l|l|}
\hline SCORE & Mid-Point $(\mathbf{X})$ & Pre-Test & Post- Test & $\mathbf{d}=\mathbf{x}-\mathbf{4 5 . 5}$ & $\mathbf{f d 1}$ & $\mathbf{f d 2}$ \\
\hline $0-10$ & 5 & 0 & 0 & -40.5 & 0 & 0 \\
\hline $11-20$ & 15.50 & 2 & 0 & -30 & -60 & 0 \\
\hline $21-30$ & 25.5 & 2 & 2 & -20 & -40 & -40 \\
\hline $31-40$ & 35.5 & 11 & 2 & -10 & -110 & -20 \\
\hline $41-50$ & 45.5 & 8 & 4 & 0 & 0 & 0 \\
\hline $51-60$ & 55.5 & 5 & 2 & 10 & 50 & 20 \\
\hline $61-70$ & 65.5 & 1 & 7 & 20 & 20 & 140 \\
\hline $71-80$ & 75.5 & 1 & 8 & 30 & 30 & 240 \\
\hline $81-90$ & 85.50 & 0 & 4 & 40 & 0 & 160 \\
\hline $91-100$ & 95.50 & 0 & 1 & 50 & 0 & 50 \\
\hline TOTAL & & $\mathbf{3 0}$ & $\mathbf{3 0}$ & $\mathbf{4 9 . 5}$ & $\mathbf{- 1 1 0}$ & $\mathbf{5 5 0}$ \\
\hline
\end{tabular}

Source: Researcher's field survey, 2019.

Where $\mathrm{fd}_{1}=$ pre-test and $\mathrm{fd}_{2}=$ post-test

Mean of pre-test $=\mathrm{A}+\frac{\Sigma f d}{\Sigma f}$ 


$$
=45.5+\frac{-110}{30}=31.83
$$

Mean of post-test $=\mathrm{A}+\frac{\Sigma f d}{\Sigma f}$

$$
=45.5+\frac{550}{30}=53.8
$$

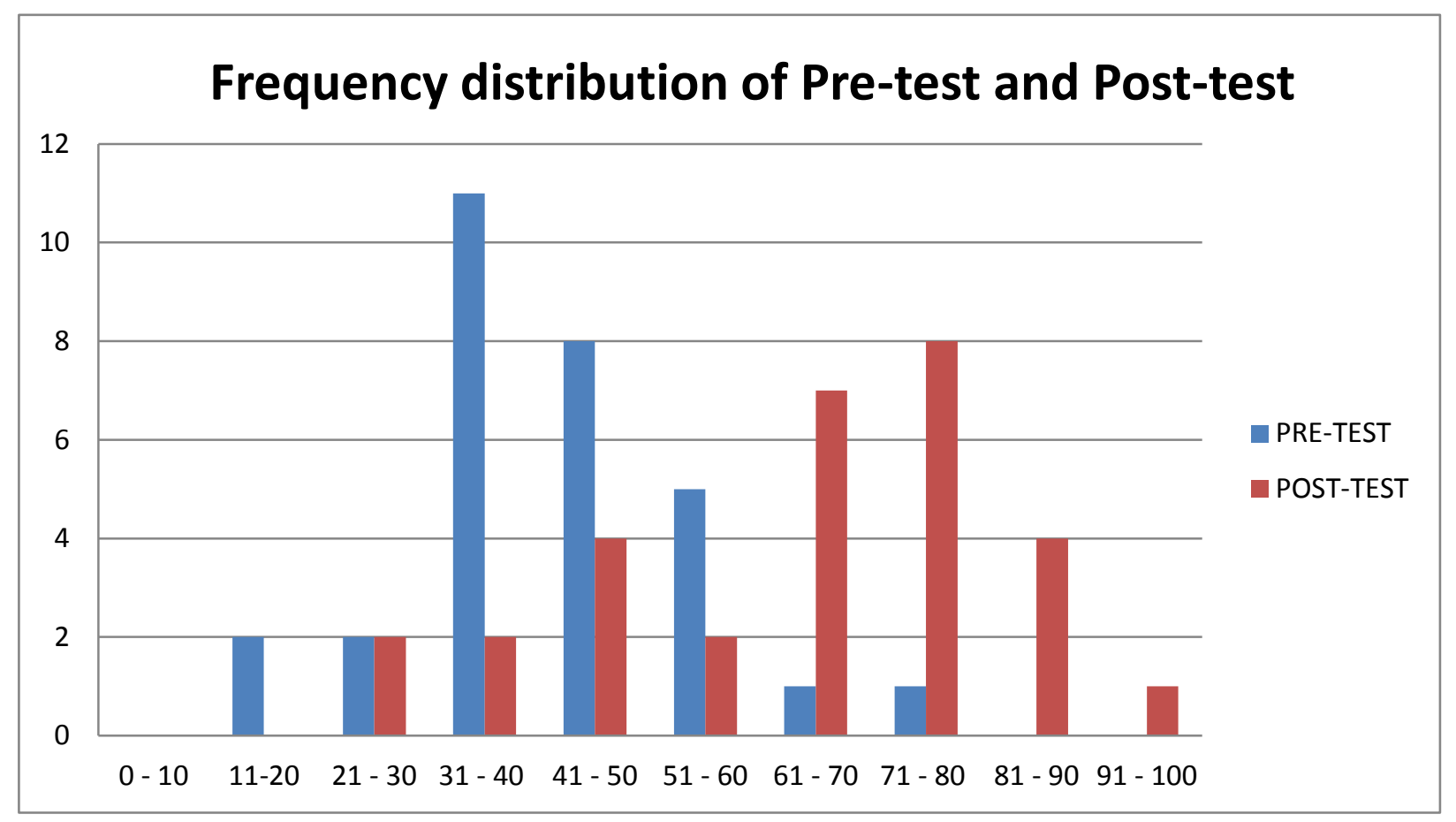

Figure 4.3 Histogram of Pre-Intervention Test and Post-Intervention Test Score

Table 4.5 shows that there is a massive improvement in students' performance on test item after the intervention. For instance, pre-test shows that no student scored above 81 marks and the mean was 31.83 while 12 students had above 81 marks and the mean was 53.8 when the post-intervention test was administered.

\section{Conclusion}

Based on the findings from the study, it can be concluded that a general intervention coming from the researcher's readiness to vary his teaching methods has helped to improve the understanding of students in mole concept and relate topics in Chemistry. Out of the class of thirty students, almost all the students appreciated the efforts of the teacher to improve understanding of student, through the various teaching techniques The use of constructivist approach significantly enhanced the student understanding of mole concept as it can be seen from the performance of students in the post-intervention test

\section{References}

[1.] Ayoade, O. E. (2012). Bridging Theory and Practice: Application of Constructivist Tenets to the Teaching of Reaction Stoichiometry. An International Journal of Science and Technology, 1(1), 144-163.

[2.] Bello, M. (2018). Effects of Inquiry and Lecture Methods of Teaching on Students 'Academic Performance a nd Retention Ability Among N . C . E 1 Chemistry Students., Open Access Journal of Chemistry, 2(3), 1-8.

[3.] DeQuadros, A. L., Da-Silva, D. C., Silva, F. C., de Andrade, F. P., Aleme, H. G., Tristão, J. C., Oliveira, S. R., Santos, L.S. and DeFreitas-Silva, G. (2011). The knowledge of chemistry in secondary education: difficulties from the teachers' viewpoint. Educación química. versión impresa ISSN 0187-893X. Educ. quím vol.22 no.3 México.

[4.] Driver, R., Asoko, H., Leach, J., Mortimer, E. and Scott, P. (1994). Constructing scientific knowledge in the classroom. Educational Researcher, 23(4), 5-12. 
[5.] Indriyanti, N. (2016). The mole concept: Students' misconception, difficulties, and the challenge. Publisher: Schüling Verlag. ISBN: 978-3-86523-276-2

[6.] Jashim, U. A. (2009). Action Research: A New Look. Journal Kasbit Business, 2, 19-32.

[7.] Jennifer, M. (2002). Qualitative Researching (2nd Edition). London: SAGE Publications Ltd.

[8.] Kamarudin, N. A. \& Halim, N. D. (2014). Learning Concept of Mole via Needham's Five Phases to Overcome Students' Alternative Concepts, 1(1).

[9.] Olusegun, S. (2015). Constructivism Learning Theory: A Paradigm for Teaching and Learning. IOSR Journal of Research \& Method in Education,5(6), 66-70. http://doi.org/10.9790/7388-05616670

[10.] Polit, D.F. and Hungler, B.P. (1999). Nursing Research: Principles and Methods. 6th Edition. Philadelphia: Lippincott.

[11.] Shadreck, M., \& Enunuwe, O. C. (2018). Recurrent Difficulties : Stoichiometry problem-solving, African Journal of Educational Studies in Mathematics and Sciences, 14, 25-31.

[12.] Strack, R., Marques, M. and Del Pino, J. C. (2009). For another path in the construction of knowledge in Chemistry Education, Química Nova na Escola, 31 (1), 18-22.

[13.] Yasmeen, G. (2008). Action research : an approach for the teachers in higher education, Journal of Educational Technology, 7(4).

[14.] Wilhelm, K., Friedmann, M. and Erickson, E. H. (1998). Hyperlearning-where projects, inquiry, and technology meet Stenhouse. Publisher.p.31. 